BULLETIN Bulletin hispanique

HISPANIQUE Université Michel de Montaigne Bordeaux

114-1 | 2012

Varia

\title{
Almudena Grandes, El corazón helado
}

Maxi Tusquets editores, Barcelona, 2011 (primera edición 2007)

María del Mar López-Cabrales

\section{CpenEdition}

\section{Journals}

Edición electrónica

URL: http://journals.openedition.org/bulletinhispanique/1974

DOI: 10.4000/bulletinhispanique. 1974

ISSN: 1775-3821

Editor

Presses universitaires de Bordeaux

\section{Edición impresa}

Fecha de publicación: 1 junio 2012

Paginación: 498-500

ISBN: $978-2-86781-812-7$

ISSN: 0007-4640

Referencia electrónica

María del Mar López-Cabrales, «Almudena Grandes, El corazón helado », Bulletin hispanique [En línea], 114-1 | 2012, Publicado el 27 mayo 2013, consultado el 22 septiembre 2020. URL : http://

journals.openedition.org/bulletinhispanique/1974; DOI : https://doi.org/10.4000/bulletinhispanique. 1974

Este documento fue generado automáticamente el 22 septiembre 2020

Tous droits réservés 


\title{
Almudena Grandes, El corazón helado
}

Maxi Tusquets editores, Barcelona, 2011 (primera edición 2007)

\author{
María del Mar López-Cabrales
}

\section{REFERENCIA}

Almudena Grandes, El corazón helado. - Barcelona, Maxi Tusquets editores, 2011

(primera edición 2007).

1 «-Como mi abuelo no era judío polaco, sino un rojo español, no tuvo la suerte de que los nazis lo gasearan. [...] Arucas fue el pueblo que más tardó en rendirse [...]. A lo mejor, por eso los falangistas pensaron que gastar balas iba a ser un despilfarro. Así que cogieron a mi abuelo y a otros sesenta y tantos republicanos de por allí, los tiraron en un pozo y les echaron cal viva por encima, tampoco demasiada, la justa para que los de arriba no pudieran salir, se conoce que estaban por ahorrar... [...]. En Auschwitz fueron más compasivos, porque a los de Arucas les costó mucho trabajo morirse, ¿sabes?, casi una semana. Y como lloraban, y se quejaban, y la cal resplandecía por las noches, la gente del pueblo empezó a llamar a aquel sitio el pozo de los gritos de las brujas, porque lo que pasaba allí parecía cosa de brujería. Eso decían, y seguían durmiendo de un tirón. [...] he estado en el pozo, y lo he visto, y he llevado flores y siempre hay flores, unas secas, otras frescas, todas amontonadas encima de la tapa» (521-522). Las mismas flores que se encuentran en la tapia del cementerio del Este, el cementerio de la Almudena en Madrid, donde se fusilaron a casi tres mil personas en la posguerra y hay flores encajadas en los agujeros que dejaron las balas (1230).

Estos y otros hechos espeluznantes de la historia del siglo XX de España son narrados en El corazón helado, una de las novelas más conseguidas de la fructífera escritora Almudena Grandes, nacida en Madrid en 1960. El corazón helado ha ganado el Premio de la Fundación Lara, el de los Libreros de Madrid y de Sevilla, el Carige en Italia, y el Prix Mediterranée en Francia. Los temas de la guerra civil española, la posguerra y la dictadura franquista y cómo estos hechos históricos han influido en la sociedad 
española actual son presentados en este libro de manera sorprendente a través de la vida de dos familias de Torrelodones: La familia Fernández y la familia Carrión.

La familia Fernández siempre fue republicana y permaneció en España durante la guerra civil: el padre para estar al servicio de la Junta y los dos hijos, Mateo e Ignacio, para luchar en el frente. Mateo muere fusilado e Ignacio, tras salvarse de la muerte en varias ocasiones, consigue llegar a Francia, donde residen sus padres y sus hermanas desde el final de la guerra civil.

4 Por otro lado, La familia Carrión está marcada por una figura femenina fuerte: Teresa, maestra y activista política republicana convencida, que se marcha con su amante para seguir luchando por la República y se lleva a su hija con ellos. El otro hijo de Teresa, Julio, se queda con su padre que termina su vida alcoholizado. Julio Carrión tiene claro que no quiere ser como su padre. Sin escrúpulos y estando siempre de parte de los vencedores, hace fortuna aprovechándose de las riquezas dejadas en España por la familia Fernández. Los nuevos Carrión, con Julio a la cabeza, forman una familia numerosa y viven cómodamente en un gran piso de Madrid durante la dictadura de Franco. Los Fernández, en el exilio, intentan inventarse una vida nueva, sin olvidar nunca lo que dejaron atrás, sus raíces, sus identidades.

5 El momento histórico llega finalmente, Franco fallece y los españoles exiliados festejan su muerte en las calles de París. Ignacio Fernández vuelve a Madrid de visita y lleva a su nieta Raquel Fernández Perea a casa de los Carrión, portando los documentos que acreditan el verdadero propietario de sus inmuebles y territorios. Carrión trata de no dar importancia a esta visita y Fernández se despide, diciendo que algún día recibiría su merecido. En frente de su nieta, en una cafetería de Madrid, Ignacio Fernández llora en silencio la injusticia.

Con el paso de los años, Raquel Fernández Perea, que trabaja en un banco de Madrid, se encuentra en la necesidad de vender su piso y comprueba -una mueca del destino-que la empresa compradora pertenece a la familia Carrión. Conocedora de la historia de su familia, Raquel da una serie de pasos para que Julio Carrión pague por lo que hizo. Finalmente, después de sentirse acorralado, Julio Carrión fallece y Raquel decide ir al entierro para volver a ver a los miembros de la familia Carrión desde lejos. Allí se produce el primer encuentro entre Raquel y Álvaro, hijo pequeño de los Carrión, profesor de física de la universidad y el único varón que decidió no trabajar en la empresa familiar. El enamoramiento de ambos cambiará la historia de las familias Fernández y Carrión que, después de tantos años de silencio, habrán de rendir cuentas por un pasado compartido e ignorado.

7 Almudena Grandes realiza un trabajo muy meritorio al ir contando las vidas de estas dos familias en el entramado histórico de un país dividido en dos Españas. Se dan constantes cambios de tiempo, del presente, la relación entre Raquel y Álvaro, al pasado, la guerra, el exilio, la vida durante la dictadura y el regreso de los exiliados. Se dan innumerables cambios de espacio: Madrid, París, el frente, las ciudades, los pueblos, Rusia, las cárceles, la angustia de la gente, las casas de las familias de clase alta, de los vencedores, y las de los vencidos, las casas de los pobres, los cementerios. Así mismo, en la novela, se dan constantes cambios de voces, de sucesos históricos, verídicos y novelados... todo el dolor de un pueblo contado con gran precisión y coherencia. Una técnica pulida que a veces roza en la reiteración, necesaria para que a las palabras no se las lleve el viento, para que no se olviden. 
8 Los temas del olvido, la indiferencia y el engaño son los ejes centrales de El corazón helado. Los habitantes de Arucas, como queda dicho, bautizan el pozo donde están agonizando con cal viva otros seres humanos «el pozo de los gritos de las brujas» y siguen durmiendo, como si no estuviera pasando nada. Esta misma frialdad caracterizó a parte de la sociedad alemana o argentina, por poner dos ejemplos del siglo pasado, cuando, a sabiendas de lo que estaba sucediendo en sus países, sus habitantes se encogían de hombros y decían «algo habrán hecho». Igualmente, los personajes de $E l$ corazón helado se mueven de manera impasible por las páginas de esta novela como si nunca hubiera pasado nada. Los únicos seres que no se rinden ante lo obvio y que luchan hasta el final son Álvaro Carrión y Raquel Fernández. Ambos son hijo y nieta de dos hombres que confiaron uno en el otro, porque en tiempos de guerra «hoy te ayudo a ti, porque mañana puede que tú me ayudes». Pero también «puede que me destruyas», dependiendo de qué tipo de persona seas. El arte de la guerra, como bien se expresa en varias ocasiones en la novela, es el arte del engaño, algo que entendió perfectamente Ignacio Fernández Muñoz en el frente, pero que supo aplicar a su vida. Julio Carrión cuando lucha en el frente se da cuenta de que será un triunfador, porque siempre estará con los vencedores, sin importarle el precio que tenga que pagar por ello. Hombre sin ideales políticos, Julio Carrión posee dos carnets, el de la JSU (Juventudes socialistas Unificadas) y el de la División Azul, y los utilizará indistintamente para conseguir, con «el corazón helado», sus objetivos: salvarse y enriquecerse.

El engaño en esta novela funciona en muchas direcciones. El primer gran engaño se opera dentro de la sociedad española de guerra, posguerra y democracia, pero también dentro de la guerra civil española, en las mismas filas republicanas. En la historia novelada, Julio Carrión engaña a la familia Fernández, de la misma manera que Raquel Fernández Perea engaña al amor de su vida, Álvaro Carrión, al contarle las circunstancias que le hicieron aparecer en el entierro de su padre. Álvaro igualmente engaña a su mujer, Mai. Sin embargo, es la madre de Álvaro Carrión, Angélica Otero, la que representa el grado máximo de la infamia y del engaño, al no inmutarse en absoluto cuando su hijo le pide explicaciones de por qué su abuela entregó al marido de su prima para que fuera fusilado, y de por qué su padre se enriqueció engañando. La madre de Álvaro no se despeina, no sufre, ignora de manera indiferente las acusaciones de su hijo, se fuma un cigarro, y sólo le pide que le siga llevando de visita a su nieto y, con frialdad, le aconseja que se corte el pelo porque así estará más favorecido. Álvaro se marcha de la casa con el alma partida.

10 La generación de los hijos de la infamia -los Carrión Otero- sufre, se pelea, reacciona de manera diferente ante los hechos familiares; sin embargo, los padres siguen sus vidas de manera impasible, con frialdad, con «el corazón helado», gracias a la indiferencia, al olvido y al engaño. Raquel Fernández Perea representa a la generación de los nietos de los vencidos, del bando republicano, la persona que al final va a hacer justicia contra la infamia de quienes se enriquecieron a costa de quienes perdieron la guerra. Raquel intenta vengar a sus abuelos y, cuando está a punto de hacerlo, Julio Carrión fallece, aparece -otra mueca del destino-Álvaro en su vida, le regala un péndulo caótico y le explica que «el todo es igual a la suma de las partes cuando las partes se ignoran entre sí». Esta frase refleja la historia y la intrahistoria de la España del siglo XX.

11 La historia ha demostrado que la política del perdón, del olvido y del silencio como pacto nacional para seguir conviviendo nunca sirve de nada. Se perdona, pero no se 
olvida, porque las generaciones venideras están marcadas por el pasado familiar e histórico. Ya sea a nivel personal, de la pequeña historia, o a nivel nacional, histórico con mayúsculas, los que olvidan son los que no tienen identidad. No se puede construir un país sobre los cadáveres de cientos de miles de personas, esperar que éstos no se remuevan en sus tumbas-fosas y sus descendientes permanezcan callados para siempre. Las dos Españas, cantadas por Antonio Machado en el poema que da título a esta novela, siguen vivas en la actualidad y están magistralmente representadas en este texto ambicioso y construido por esta técnica depurada que caracteriza a la obra de Almudena Grandes. Esta autora nos demuestra de nuevo su gran conocimiento histórico y su capacidad para escuchar las vidas de un pueblo que aún sangra por la Ley de Responsabilidades Políticas (1939) que prolongó su vigencia durante treinta largos años, hasta el Decreto Ley del 69, firmado por Franco, por el que prescribían todos los delitos cometidos antes de 1 de abril de 1939. Una de las dos Españas, la de los vencidos, volvió a abrir sus heridas y, a la vez, a respirar, a evitar el olvido, con la Ley de Memoria Histórica (2007) que tantas satisfacciones y polémicas ha suscitado. El corazón helado es buena muestra de ello, sus páginas pasan y cuanto más leemos, más queremos saber, más queremos entender este pasaje incomprensible de la historia de un país que comienza a descongelar su corazón y a descifrar interrogantes abiertos durante décadas. 